\title{
Aspects of Resonance: Comparison of High Speed Films and Overtone Measurements
}

Mette Pedersen MD*, Bilal Hussain Akram, Mohammad Shezad Mahmood, Anne Alexius Agersted, Anders Jønsson and Sanilla Mahmood

The Medical Centre, Østergade 18, 3, 1100 Copenhagen, Denmark

*Corresponding author: Mette Pedersen MD, The Medical Centre, Østergade 18, 3, 1100 Copenhagen, Denmark, Tel: +4531126184; E-mail: m.f.pedersen@dadlnet.dk Rec date: Dec 10, 2015; Acc date: Dec 18, 2015; Pub date: Dec 21, 2015

Copyright: (c) 2015 Pedersen M, et al. This is an open-access article distributed under the terms of the Creative Commons Attribution License, which permits unrestricted use, distribution, and reproduction in any medium, provided the original author and source are credited.

\begin{abstract}
A comparison has been made simultaneously of high speed films, acoustical analysis and overtone analysis with "VoceVista" and "Sygyt Ltd". The overtones software was compared with acoustical analysis. Till now formants from $1000 \mathrm{~Hz}-5000 \mathrm{~Hz}$ seems to be interesting using fundamental frequency of speech with $110 \mathrm{~Hz}$ in males and $220 \mathrm{~Hz}$ in females. The variation of the 3 formants from $1000 \mathrm{~Hz}-5000 \mathrm{~Hz}$ was between $18-25 \%$ for normal persons. Glottal analysis tools from Erlangen showed no evidence of traditional acoustical voice analysis. With the new overtone analyzer (Sygyt Ltd.) we have a tool for measuring pathological voices combined with high speed films.
\end{abstract}

Keywords: Speed films; Overtone analysis; Electroglottography

\section{Introduction}

There are new apparatuses on the market-based on voice researchwhere the patient can benefit from advanced diagnostics of overtones.

A clinical routine with high speed films includes kymography, electroglottography and quantitative measures of the movement of the left and right vocal fold. It was showed that irregularity of the two vocal folds against each other hardly ever was the case. So airflow correction as used traditionally for correction of voices is doubted. Therefore, new approaches had to be made, especially not related to airflow. Documentation of overtones measures up to $20000 \mathrm{~Hz}$ (or more) with a stable and well established overtone analyzer leads to new clinical experiences - since it is made in a clinic friendly easy way even cheap. Next is to optimize the analysis of larynx functions with among others Optical coherence tomography and Narrow Band Imaging to understand the mucosal function.

With high speed films combined with electroglottography, kymography, and overtones, nuanced evaluation of the voice is possible and to some extend evidence based. The software of high speed films includes quantitative measures of the closure of the vocal folds as well as stiffness, a calculation of maximal amplitude versus maximal speed of the vocal folds. In all 345 measurements of the voice can be made with the software that is on the market-"Glottal analyses tools" from Erlangen Germany. Acoustical analysis as well as glottal area waveforms calculations are made online on high speed films. The most used acoustical examination do not give sufficient or reliable information in pathology.

\section{Method}

The literature has been reviewed extensively for clinical aspects of resonance/overtones/harmonics: A British Library search of resonance of the human voice included search words: "voice and resonance" for the latest two years found 1610 references out of which some interesting results have been studied especially from the book by Donald Miller.
We have compared the "VoceVista" by Donald Miller with the newer software "Sygyt Ltd" which is easy to use and we have found them comparable.

In pathology there are no answers of: why one singer is better than another. Many demonstrations have been made of average formant analysis during singing of melodies - sentences - by perfect singers (Pavarotti etc.). The challenge is, with one good overtone measuring method, to explain the patient complaints of various kinds of hoarseness, in an evidence based way in the clinic.

We tried to compare the methods of overtone/harmonics analysis of "VoceVista" with "Sygyt Ltd" to find out if the two methods were comparable so that result could be used with both analyses. At least twelve subjects are needed statistically to describe the distribution of a normal material. This was also the case of the analysis of the overtones of the human voice.

In the literature the fundamental frequency (F0), in a scientifically usable way in pathology, was seldom defined in the formant analyses of singers. Therefore, we decided to compare the fundamental frequencies (F0) of voice as used in speech and harmonic overtones hereof, just to have a value for pathology. We also compared the sound analysis of the overtones of the human voice based on the fundamental frequency in speech comparing "VoceVista" with the more flexible "Sygyt Ltd".

We compared 12 normal voices of persons without voice complaints with measures of "VoceVista" and "Sygyt Ltd". 12 persons were statistically enough in a prospective cohort study to characterize a normal material and it was used to identify major differences between the two systems.

As the voices of patients are very different in nature, it is a challenge to identify the vocal problems. In order to identify the pathological problem in the clinic, a sensitive and specific measurement is needed. In the literature formant measurements over several seconds have been analyzed of famous singers without description of F0. In a clinical situation singing overtones and the measurements of them will vary extremely much and results can be understood in many ways. So to begin with, a clinical approach was made of the mean fundamental 
Citation: Pedersen MDM, Akram BH, Mahmood MS, Agersted AA, Jønsson A, et al. (2015) Aspects of Resonance: Comparison of High Speed Films and Overtone Measurements. J Health Edu Res Dev 3: 145. doi:10.4172/2380-5439.1000145

Page 2 of 7

frequency (F0). The formants as defined with "VoceVista" which measures to $5000 \mathrm{~Hz}$ were compared with "Sygyt Ltd." that measures to $20.000 \mathrm{~Hz}$. They were made only over $1000 \mathrm{~Hz}$ to exclude articulation related variations.

\section{VoceVista}

\section{Spectrogram:}

Up to $5000 \mathrm{~Hz}$

Fundamental frequency of speech was chosen to measure overtones:

Male: $110 \mathrm{~Hz}$

Female: $220 \mathrm{~Hz}$

\section{Sygyt (Ltd.)}

\section{Spectrogram:}

Up to $20000 \mathrm{~Hz}$

Fundamental frequency of speech as chosen for measures to be used in pathology:

\section{Male: $110 \mathrm{~Hz}$}

Female: $220 \mathrm{~Hz}$

\section{Formants}

We have defined one formant as bundle of harmonic scale which combined represent the formant.

The harmonic overtone with the highest point in $\mathrm{dB}$ reflected in the formant was selected.

The amplitude of the selected harmonic overtones was read from the lowest to the highest point.

The first three formants over $1000 \mathrm{~Hz}$ were measured and the associated $\mathrm{dB}$ for each formant noted. Some formants less than 1000 $\mathrm{Hz}$ were noted in parentheses, even if they are articulation related.

Normal persons were used, 6 males and 6 females were analyzed. The fundamental frequency of speech (F0) during intonation of "ah" was defined, and a prospective cohort study of the formant placements of F0 with "VoceVista" up to $5000 \mathrm{~Hz}$ and "Sygyt Ltd" up to $20.000 \mathrm{~Hz}$ was made.

From a statistical point of view, measurements of the same millisecond (ms) was necessary to compare the formants of the two systems in a test of intonation, see Figures 1 and 2.

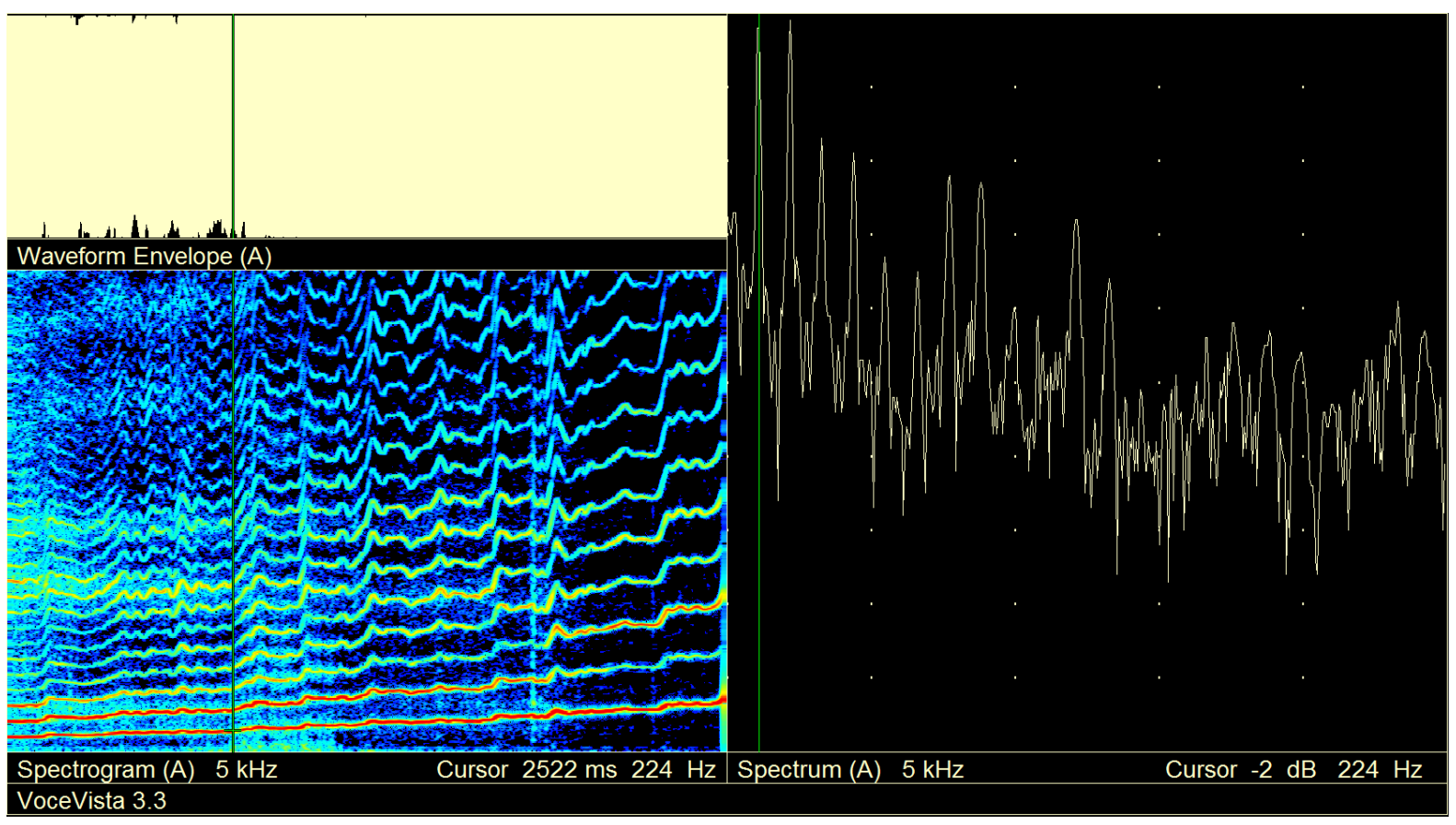

Figure 1: "VoceVista" up to $5000 \mathrm{~Hz}$ compared with the same sound of "Sygyt Ltd." up to $5000 \mathrm{~Hz}$.

\section{Results}

"VoceVista" results of formants from 1000 up to $5000 \mathrm{~Hz}$ named $\mathrm{Fx}$, $\mathrm{Fy}$, and $\mathrm{Fz}$ in a prospective cohort study of 12 normal persons with the F0 nearest to 220 and $110 \mathrm{~Hz}$. (Table 1).
"Sygyt Ltd." results of sound formants from over $1000 \mathrm{~Hz}$ up to 5000 $\mathrm{Hz}$ with 110 and $220 \mathrm{~Hz}$ as basis of overtone measures of the same 12 normal persons (Table 2). 
Citation: Pedersen MDM, Akram BH, Mahmood MS, Agersted AA, Jønsson A, et al. (2015) Aspects of Resonance: Comparison of High Speed Films and Overtone Measurements. J Health Edu Res Dev 3: 145. doi:10.4172/2380-5439.1000145

Page 3 of 7

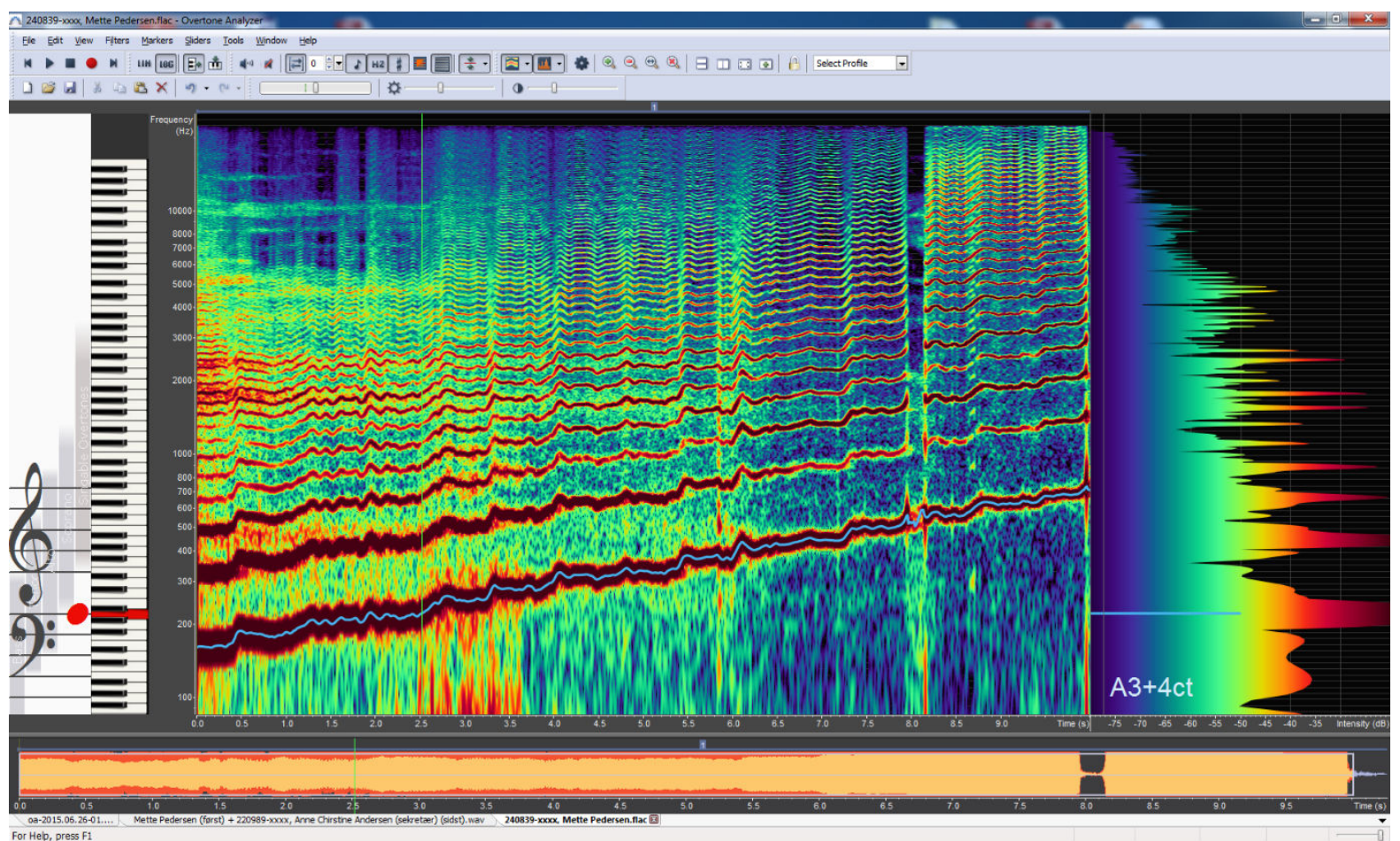

Figure 2: “Sygyt Ltd.” overtone analyzer to $20000 \mathrm{~Hz}$ with formant detection to the hight at $220 \mathrm{~Hz}$, a normal femlae's voicers.

\begin{tabular}{|c|c|c|c|c|c|c|c|c|c|c|c|c|c|c|}
\hline \multicolumn{15}{|c|}{ A: "VoceVista" Results } \\
\hline Nr. & Name & Gender & Age & ms & $\mathrm{FO}(\mathrm{Hz})$ & $\mathrm{FO}(\mathrm{dB})$ & $\begin{array}{l}(\mathrm{Fa}) \\
(\mathrm{Hz})\end{array}$ & $\mathrm{Fa}(\mathrm{dB})$ & $F x(H z)$ & $F x(d B)$ & $\mathrm{Fy}(\mathrm{Hz})$ & Fy (dB) & $\mathrm{Fz}(\mathrm{dB})$ & $\mathrm{Fz}(\mathrm{dB})$ \\
\hline 1 & MP-A & $\mathrm{F}$ & 75 & 2522 & 224 & 62 & & & 1546 & 38 & 2430 & 36 & 4662 & 23 \\
\hline 2 & ACA-A & $\mathrm{F}$ & 25 & 14154 & 224 & 46 & & & 1558 & 28 & 2906 & 24 & 3886 & 16 \\
\hline 3 & LTC-A & $\mathrm{F}$ & 40 & 2335 & 224 & 43 & & & 1113 & 38 & 2304 & 25 & 3525 & 18 \\
\hline 4 & $\mathrm{KJH}-\mathrm{A}$ & $\mathrm{F}$ & 47 & 2668 & 224 & 60 & & & 1552 & 48 & 2220 & 35 & 3766 & 25 \\
\hline 5 & SM-A & $\mathrm{F}$ & 24 & 308 & 224 & 49 & & & 1762 & 30 & 2864 & 23 & 4350 & 14 \\
\hline 6 & NBL-A & $\mathrm{F}$ & 25 & 616 & 224 & 46 & & & 1762 & 29 & 2202 & 24 & 3929 & 24 \\
\hline 7 & AJ-A & M & 24 & 2551 & 107 & 48 & & & 1768 & 19 & 3321 & 15 & 4247 & 17 \\
\hline 8 & MSM-A & $M$ & 23 & 567 & 107 & 40 & & & 1624 & 22 & 2430 & 30 & 3243 & 30 \\
\hline 9 & BHA-A & M & 22 & 883 & 107 & 38 & & & 1576 & 28 & 2286 & 20 & 3122 & 20 \\
\hline 10 & MO-A & M & 28 & 1063 & 107 & 52 & & & 1546 & 35 & 2151 & 18 & 3327 & 20 \\
\hline 11 & AH-A & M & 16 & 2320 & 107 & 42 & & & 1251 & 20 & 2290 & 26 & 3868 & 22 \\
\hline 12 & JJ-B & M & 33 & 847 & 107 & 46 & & & 1095 & 28 & 3303 & 26 & 4079 & 24 \\
\hline
\end{tabular}

Table 1: "VoceVista" results 12 normal persons. 
Citation: Pedersen MDM, Akram BH, Mahmood MS, Agersted AA, Jønsson A, et al. (2015) Aspects of Resonance: Comparison of High Speed

Page 4 of 7

\section{B: "Sygyt" Results}

\begin{tabular}{|c|c|c|c|c|c|c|c|c|c|c|c|c|c|c|c|c|}
\hline \multirow[b]{2}{*}{ Nr. } & \multirow[b]{2}{*}{ Name } & \multirow[b]{2}{*}{ Gender } & \multirow[b]{2}{*}{ Age } & \multirow[b]{2}{*}{ ms } & \multirow[b]{2}{*}{$\begin{array}{l}\text { F0 } \\
\text { (Hz) }\end{array}$} & \multirow[b]{2}{*}{$\begin{array}{l}\text { F0 } \\
\text { (dB) }\end{array}$} & \multirow[b]{2}{*}{$\begin{array}{l}(\mathrm{Fa}) \\
(\mathrm{Hz})\end{array}$} & \multirow[b]{2}{*}{$\begin{array}{l}(\mathrm{Fa}) \\
(\mathrm{dB})\end{array}$} & \multirow[b]{2}{*}{$\mathrm{Fx}(\mathrm{Hz})$} & \multirow[b]{2}{*}{$\begin{array}{l}F x \\
\text { (dB) }\end{array}$} & \multirow[b]{2}{*}{$\mathrm{Fy}(\mathrm{Hz})$} & \multirow[b]{2}{*}{$\begin{array}{l}\text { Fy } \\
\text { (dB) }\end{array}$} & \multirow[b]{2}{*}{$\mathrm{Fz}(\mathrm{Hz})$} & \multirow[b]{2}{*}{$\begin{array}{l}\mathrm{Fz} \\
\text { (dB) }\end{array}$} & \multicolumn{2}{|c|}{ Total Range in $\mathrm{Hz}$} \\
\hline & & & & & & & & & & & & & & & Lowest & Highest \\
\hline 1 & MP-B & $\mathrm{F}$ & 75 & 2520 & 220 & 58 & 436 & 55 & 1545 & 31 & 2433 & 35 & 4662 & 20 & 231 & 1126 \\
\hline 2 & ACA-B & $\mathrm{F}$ & 25 & 14150 & 220 & 43 & 436 & 52 & 1555 & 24 & 2874 & 33 & 3881 & 13 & 174 & 610 \\
\hline 3 & LTC-B & $F$ & 40 & 2330 & 220 & 43 & 403 & 48 & 1114 & 40 & 2304 & 20 & 3526 & 16 & 190 & 874 \\
\hline 4 & KJH-B & $\mathrm{F}$ & 47 & 2665 & 220 & 58 & 441 & 55 & 1539 & 42 & 2201 & 26 & 3762 & 19 & 151 & 760 \\
\hline 5 & SM-B & $F$ & 24 & 310 & 220 & 45 & 441 & 56 & 1765 & 25 & 2869 & 22 & 4333 & 12 & 211 & 491 \\
\hline 6 & NBL-B & $\mathrm{F}$ & 25 & 620 & 220 & 51 & 441 & 49 & 1765 & 29 & 2201 & 21 & 3924 & 25 & 196 & 703 \\
\hline 7 & AJ-B & $M$ & 24 & 2560 & 110 & 48 & 333 & 47 & 1781 & 22 & 3321 & 23 & 4247 & 22 & 88 & 714 \\
\hline 8 & MSM-B & $M$ & 23 & 570 & 110 & 38 & 344 & 41 & 1625 & 21 & 2470 & 25 & 3246 & 19 & 98 & 615 \\
\hline 9 & BHA-B & $M$ & 22 & 880 & 110 & 44 & 452 & 59 & 1571 & 25 & 2255 & 22 & 3133 & 17 & 99 & 853 \\
\hline 10 & MO-B & $M$ & 28 & 1060 & 110 & 48 & 333 & 44 & 1550 & 27 & 2131 & 21 & 3332 & 22 & 102 & 538 \\
\hline 11 & $\mathrm{AH}-\mathrm{B}$ & $M$ & 16 & 2320 & 110 & 48 & 333 & 38 & 1254 & 20 & 2217 & 24 & 3865 & 20 & 110 & 365 \\
\hline 12 & JJ-B & $M$ & 33 & 850 & 110 & 42 & 549 & 45 & 1098 & 24 & 3305 & 23 & 4107 & 21 & 107 & 683 \\
\hline
\end{tabular}

Table 2: "Sygyt Ltd" results of 12 normal persons.

Comparison of "Sygyt Ltd" and "VoceVista" are presented in Table 3. The variation in $\%$ is presented: $\mathrm{Fx}(\mathrm{Hz}) 18 \%, \mathrm{Fy}(\mathrm{hz}) 25 \%, \mathrm{Fz}(\mathrm{Hz})$ $20 \%$.

\begin{tabular}{|c|c|c|c|c|c|c|c|c|c|c|c|}
\hline Nr. & Name & Gender & Age & Fo (Hz) & $\mathrm{FO}(\mathrm{dB})$ & $\mathrm{Fx}(\mathrm{Hz})$ & $F x(d B)$ & $\mathrm{Fy}(\mathrm{Hz})$ & $\mathrm{Fy}(\mathrm{dB})$ & $\mathrm{Fz}(\mathrm{Hz})$ & $\mathrm{Fz}(\mathrm{dB})$ \\
\hline 1 & MP-B & $\mathrm{F}$ & 75 & 220 & 3 & -19 & -4 & -21 & 2 & 862 & -10 \\
\hline 2 & ACA-B & $\mathrm{F}$ & 25 & 220 & -20 & -75 & -11 & 74 & 10 & -90 & -7 \\
\hline 3 & LTC-B & $\mathrm{F}$ & 40 & 220 & -7 & -29 & -8 & -884 & -5 & -1323 & -9 \\
\hline 4 & KJH-B & $\mathrm{F}$ & 47 & 220 & -2 & -73 & 9 & -326 & -17 & -136 & -9 \\
\hline 5 & SM-B & $\mathrm{F}$ & 24 & 220 & 1 & -88 & -9 & -115 & -5 & 188 & -5 \\
\hline 6 & NBL-B & $\mathrm{F}$ & 25 & 220 & 1 & -271 & -1 & -1228 & 1 & -143 & 8 \\
\hline 7 & AJ-B & M & 24 & 110 & 13 & -42 & -6 & 909 & -7 & 932 & 2 \\
\hline 8 & MSM-B & M & 23 & 110 & 8 & -348 & -4 & -1001 & 5 & -1152 & -3 \\
\hline 9 & BHA-B & M & 22 & 110 & -6 & -11 & -5 & -801 & -3 & -898 & -8 \\
\hline 10 & MO-B & M & 28 & 110 & 6 & -610 & 2 & -1244 & 1 & -1523 & -6 \\
\hline 11 & $\mathrm{AH}-\mathrm{B}$ & M & 16 & 110 & 3 & -851 & 0 & -592 & 5 & 141 & 3 \\
\hline 12 & JJ-B & M & 33 & 110 & -18 & -3 & -12 & -4 & -2 & 28 & -3 \\
\hline \multicolumn{6}{|c|}{ Mean } & 1513.5 & 27.5 & 2548.9 & 24.33 & 3834.3 & 18.417 \\
\hline sd & & & & & & 273.796 & 5.9461 & 639.65 & 6.995 & 803.97 & 5.6159 \\
\hline
\end{tabular}


Citation: Pedersen MDM, Akram BH, Mahmood MS, Agersted AA, Jønsson A, et al. (2015) Aspects of Resonance: Comparison of High Speed

Page 5 of 7

\begin{tabular}{|l|l|l|l|l|l|l|l|l|l|l|l|}
\hline cv & & & & & & 18.0903 & 21.622 & 25.095 & 28.75 & 20.968 & 30.493 \\
\hline
\end{tabular}

Table 3: Comparing "Sygyt Ltd." and "VoceVista”.

The same sound recording was analyzed of the two different software. The comparison is based on varying time points of F0 for the "Sygyt Ltd" and the "VoceVista". Notice that the coefficient of variation is $18-25 \%$.
The fundamental frequency changes over time during the sound recording. As seen on table 4 it was essential that the results of the "Sygyt Ltd" and "VoceVista" was evaluated at the exact same millisecond for the sound recording.

\begin{tabular}{|c|c|c|c|c|c|c|c|c|c|c|c|c|}
\hline Nr. & Name & Gender & Age & $\mathrm{F} 0(\mathrm{~Hz})$ & $\mathrm{FO}(\mathrm{dB})$ & $\mathrm{Fx}(\mathrm{Hz})$ & $F x(d B)$ & $\mathrm{Fy}(\mathrm{Hz})$ & $\mathrm{Fy}(\mathrm{dB})$ & $\mathrm{Fz}(\mathrm{Hz})$ & $\mathrm{Fz}(\mathrm{dB})$ & $\mathrm{Fz}(\mathrm{dB})$ \\
\hline 1 & MP-B & $\mathrm{F}$ & 75 & 220 & -4 & -1 & -7 & 3 & -1 & 862 & 0 & -3 \\
\hline 2 & ACA-B & $\mathrm{F}$ & 25 & 220 & -3 & -3 & -4 & -32 & 9 & -90 & -5 & -3 \\
\hline 3 & LTC-B & $\mathrm{F}$ & 40 & 220 & 0 & 1 & 2 & 0 & -5 & -1323 & 1 & -2 \\
\hline 4 & KJH-B & $\mathrm{F}$ & 47 & 220 & -2 & -13 & -6 & -19 & -9 & -136 & -4 & -6 \\
\hline 5 & SM-B & $\mathrm{F}$ & 24 & 220 & -4 & 3 & -5 & 5 & -1 & 188 & -17 & -2 \\
\hline 6 & NBL-B & $\mathrm{F}$ & 25 & 220 & 5 & 3 & 0 & -1 & -3 & -143 & -5 & 1 \\
\hline 7 & AJ-B & $\mathrm{M}$ & 24 & 110 & 0 & 13 & 3 & 0 & 8 & 932 & 0 & 5 \\
\hline 8 & MSM-B & $M$ & 23 & 110 & -2 & 1 & -1 & 40 & -5 & -1152 & 3 & -11 \\
\hline 9 & BHA-B & $M$ & 22 & 110 & 6 & -5 & -3 & -31 & 2 & -898 & 11 & -3 \\
\hline 10 & MO-B & M & 28 & 110 & -4 & 4 & -8 & -20 & 3 & -1523 & 5 & 2 \\
\hline 11 & $\mathrm{AH}-\mathrm{B}$ & M & 16 & 110 & 6 & 3 & 0 & -73 & -2 & 141 & -3 & -2 \\
\hline 12 & JJ-B & M & 33 & 110 & -4 & 3 & -4 & 2 & -3 & 28 & 28 & -3 \\
\hline \multicolumn{2}{|c|}{ Mean } & & & & & 1513.5 & 27.5 & 2548.42 & 24.5833 & 3834.33 & 3834.83 & 18.8333 \\
\hline sd & & & & & & 6.18098 & 3.54516 & 27.6192 & 5.29937 & 803.968 & 10.8195 & 3.98006 \\
\hline \multirow[t]{2}{*}{$\mathrm{cv}$} & & & & & & 0.40839 & 12.8915 & 1.08378 & 21.5568 & 20.9676 & 0.28214 & 21.1331 \\
\hline & & & & & & 0.75 & -2.75 & -10.5 & -0.58333 & -259.5 & 1.16667 & -2.25 \\
\hline \multicolumn{6}{|c|}{ Difference in percent of mean } & $0 \%$ & $-10 \%$ & $0 \%$ & $-2 \%$ & $-7 \%$ & $0 \%$ & $-12 \%$ \\
\hline
\end{tabular}

Table 4: Comparing "Sygyt Ltd"-"VoceVista" at the same millisecond.

The same sound recording was analyzed for the two different softwares. As the fundamental frequency (F0) changes over time during the sound recording, it was essential that the results of the "Sygyt Ltd" and "VoceVista" were evaluated at the exact same millisecond for the sound recording.

Table 4 shows the difference in formants of F0 between the "Sygyt Ltd" and the "VoceVista" sound analysis software over $1000 \mathrm{~Hz}$. As can be seen for the Fx, Fy and Fz, the mean $\mathrm{Hz}$ were 1513, 2548 and 3834, respectively with a difference between the software of $0.75,-10.5$ and $-259.5 \mathrm{~Hz}$. The difference in percentage of mean shows that the difference is 0,0 and $-7 \%$, corresponding to almost identical assessment of the formants around $1500 \mathrm{~Hz}$ and $2550 \mathrm{~Hz}$.

As "Sygyt Ltd" results of up to $20000 \mathrm{~Hz}$ can be measured, we tried to study the normal persons for a start for variation of the formants near $10000 \mathrm{~Hz}$. With "SAS program 9,4" using "the Spearman Rank correlation coefficient test", the variation was $4,3 \%$ (Table. 5 ).

\begin{tabular}{|l|l|l|l|l|l|l|l|}
\hline Nr. & Name & Gender & Age & RC (Hz) & RC (dB) & F 10k (Hz) & F 10k (dB) \\
\hline 1 & MP-B & F & 75 & 363 & 58 & 10125 & 14 \\
\hline 2 & ACA-B & F & 25 & 365 & 52 & 10615 & 27 \\
\hline 3 & LTC-B & F & 40 & 523 & 71 & 10325 & 21 \\
\hline 4 & KJH-B & F & 47 & 457 & 41 & 10142 & 16 \\
\hline 5 & SM-B & F & 24 & 415 & 49 & 9727 & 11 \\
\hline 6 & NBL-B & F & 25 & 410 & 63 & 11138 & 24 \\
\hline 7 & AJ-B & M & 24 & 205 & 63 & 10750 & 14 \\
\hline 8 & MSM-B & M & 23 & 201 & 46 & 10448 & 15 \\
\hline 9 & BHA-B & M & 22 & 224 & 49 & 10136 & 11 \\
\hline 10 & MO-B & M & 28 & 231 & 48 & 9576 & 21 \\
\hline
\end{tabular}


Citation: Pedersen MDM, Akram BH, Mahmood MS, Agersted AA, Jønsson A, et al. (2015) Aspects of Resonance: Comparison of High Speed

Page 6 of 7

\begin{tabular}{|l|l|l|l|l|l|l|l|}
\hline 11 & AH-B & M & 16 & 180 & 14 & 10571 & 17 \\
\hline 12 & JJ-B & M & 33 & 206 & 49 & 9969 & 15 \\
\hline
\end{tabular}

High speed films and acoustical measurements were made simultaneously of the prospective cohort study of the 12 normal persons, and analyzed with "Sygyt Ltd". The results of formant variation made with "Sygyt Ltd" are on the same level as "VoceVista" due to the variation of F0. Table 6 presents the variation of 3 formants

Table 5: Variation of the formants near $10000 \mathrm{~Hz}$ with "Sygyt Ltd". $1000-5000 \mathrm{~Hz}$ from acoustical measures made simultaneously with

STD 441.4833 high speed films, with acoustical setting in the high speed software by

MEAN 10293.5 Wolf Ltd.

Coefficient of Variation (CV) $\quad 4.3 \%$

\begin{tabular}{|c|c|c|c|c|c|c|c|c|c|c|c|c|c|c|}
\hline Nr. & Name & Gender & Age & $\mathrm{ms}$ & F0 (Hz) & $\begin{array}{l}\text { F0 } \\
\text { (dB) }\end{array}$ & $\begin{array}{l}(\mathrm{Fa}) \\
(\mathrm{Hz})\end{array}$ & $\begin{array}{l}\text { (Fa) } \\
\text { (dB) }\end{array}$ & $\mathrm{Fx}(\mathrm{Hz})$ & $\begin{array}{l}\text { Fx } \\
\text { (dB) }\end{array}$ & $\mathrm{Fy}(\mathrm{Hz})$ & $\begin{array}{l}\text { Fy } \\
\text { (dB) }\end{array}$ & $\mathrm{Fz}(\mathrm{Hz})$ & $\mathrm{Fz}(\mathrm{dB})$ \\
\hline 1 & MP-A & $\mathrm{F}$ & 75 & 520 & 327 & 64 & & & 1320 & 35 & 2312 & 34 & 3271 & 18 \\
\hline 2 & ACA-A & $\mathrm{F}$ & 25 & 70 & 251 & 48 & & & 1261 & 33 & 2241 & 30 & 4025 & 28 \\
\hline 3 & LTC-A & $\mathrm{F}$ & 40 & 1130 & 329 & 45 & & & 1401 & 28 & 2295 & 20 & 3357 & 9 \\
\hline 4 & KJH-A & $\mathrm{F}$ & 47 & 850 & 142 & 15 & & & 1293 & 39 & 2328 & 24 & 3028 & 27 \\
\hline 5 & SM-A & $\mathrm{F}$ & 24 & 900 & 307 & 38 & & & 1606 & 38 & 3206 & 25 & 4004 & 26 \\
\hline 6 & NBL-A & $\mathrm{F}$ & 25 & 640 & 377 & 64 & & & 1131 & 23 & 2258 & 22 & 3411 & 14 \\
\hline 7 & AJ-A & M & 24 & 120 & 216 & 56 & & & 1293 & 48 & 2371 & 40 & 3449 & 40 \\
\hline 8 & MSM-A & M & 23 & 1060 & 158 & 38 & & & 1115 & 38 & 2549 & 29 & 3341 & 21 \\
\hline 9 & BHA-A & M & 22 & 1210 & 266 & 47 & & & 1320 & 51 & 2904 & 30 & 4230 & 20 \\
\hline 10 & MO-A & M & 28 & 440 & 211 & 49 & & & 1077 & 42 & 2373 & 28 & 4694 & 19 \\
\hline 11 & $\mathrm{AH}-\mathrm{A}$ & M & 16 & 430 & 139 & 42 & & & 1385 & 23 & 2500 & 28 & 3336 & 16 \\
\hline 12 & JJ-B & M & 33 & 160 & 196 & 20 & & & 1040 & 12 & 1697 & 12 & 2204 & 19 \\
\hline \multicolumn{15}{|c|}{ Difference to Sygyt sound analysis of 12 normal persons } \\
\hline \multirow{4}{*}{\multicolumn{3}{|c|}{ Coefficient of variation (cv) }} & & mean & & & & & 1513.5 & & 2548.4 & & 3834.8 & \\
\hline & & & & $\begin{array}{l}\text { change } \\
\text { mean }\end{array}$ & & & & & 243.3 & & 128.9 & & 305.7 & \\
\hline & & & & std & & & & & 270.0 & & 632.7 & & 923.4 & \\
\hline & & & & $\mathrm{cv}$ & & & & & $18 \%$ & & $25 \%$ & & $24 \%$ & \\
\hline
\end{tabular}

Table 6: Variation of 3 formants from high speed films were of the same $\%$ variation.

\section{Results/Discussion}

The results show that formant measures are possible routinely. A normal material has been presented with a variation of the 3 formants over $1000 \mathrm{~Hz}$ of $18-25 \%$. Since the literature is calling for more evidence based studies, we refer to measuring the formants between $1000 \mathrm{~Hz}-5000 \mathrm{~Hz}$ in pathology. Formant analysis with the program "Sygyt Ltd." might be a tool not only for qualified singers, but also in pathology $[1,2]$.

From the literature we have essential documentation that evidence based voice diagnosis in pathology is lacking:

\section{Surgical versus non-surgical interventions for vocal cord nodules:}

This is a Cochrane review first published in The Cochrane Library in Issue 2, 2012 and previously updated in 2007 and 2009.

Vocal cord nodules are bilateral, benign, callous-like growths of the mid-portion of the membranous vocal folds. They are of variable size and are characterized histologically by thickening of the epithelium with a variable degree of inflammation in the underlying superficial lamina propria. They characteristically produce hoarseness, discomfort and an unstable voice when speaking or singing .

To assess the effectiveness of surgery versus non-surgical interventions for vocal cord nodules we searched the Cochrane Ear, Nose and Throat Disorders Group Trials Register; the Cochrane Central Register of Controlled Trials (CENTRAL); PubMed; EMBASE; 
Citation: Pedersen MDM, Akram BH, Mahmood MS, Agersted AA, Jønsson A, et al. (2015) Aspects of Resonance: Comparison of High Speed

CINAHL; Web of Science; BIOSIS Previews; Cambridge Scientific Abstracts; ISRCTN and additional sources for published and unpublished trials. The date of the most recent search was 9 April 2012.

When searching for randomized and quasi-randomized trials comparing any surgical intervention for vocal cord nodules with nonsurgical treatment or no treatment (including acoustical measures) no suitable trials were identified. No studies fulfilled the inclusion criteria. There is a need for high-quality randomized controlled trials to evaluate the effectiveness of surgical and non-surgical treatment of vocal cord nodules [3].

\section{Reliability of objective voice measures of normal speaking voices:}

The objective was to determine the reliability of objective voice measures used commonly in clinical practice. 18 healthy volunteers (nine males and nine females) were included. Measures of laryngeal efficiency and perturbation measures of fundamental frequency (F0) for both genders were made. For female cepstral peak prominence (CPP) had moderate reliability, whereas for males, the smooth CPP was reliable. Noise-to-harmonic ratios (NHRs) has the lowest consistency of all measures over the course. Additional research is needed to investigate which factors within the testing protocol and/or changes to the measurement instruments may lead to more consistent test results [4].

Evidence-based Clinical Voice Assessment: A Systematic Review.

To determine what research evidence exists to support the use of voice measures in the clinical assessment of patients with voice disorders.

Literature studies provide measurements results of selected acoustic, laryngeal imaging-based, auditory-perceptual, functional, and aerodynamic measures. There is clearly a pressing need for high- quality research that is specially designed to expand the evidence base for clinical voice assessment [5].

\section{Conclusion}

Measures of high speed films combined with overtones/harmonics with "VoceVista" and "Sygyt Ltd." show that they are comparable up to $5000 \mathrm{~Hz}$. "Sygyt Ltd" has a range up to $20.000-30.000 \mathrm{~Hz}$. "Sygyt Ltd." can therefore be used for formant analysis in clinical praxis for at least $10.000 \mathrm{~Hz}$ as it was done in the prospective cohort study of 12 normal patients.

The approach in clinical praxis must be simple-therefore we suggest using high speed films simultaneously to $\mathrm{F} 0$ around $110 \mathrm{~Hz}$ in males and $220 \mathrm{~Hz}$ in females analysed with "Sygyt Ltd." as a basis for voice pathology. Formant analysis and high speed films simultaneously could give much more information of treatment effect in voice pathology.

\section{References}

1. Pedersen M, Akram BH, Agersted AA (2015) Technology Advances in Diagnostics of Vocal Folds Function. Otolaryngology 5: 1-5.

2. Donald Gray Miller, (2008) Resonance in singing. Voicevista, Inside View Press.

3. Pedersen M, MC Glashan J (2012) Surgical versus non-surgical interventions for vocal cord nodules (Review). The Cochrane Library pp: $1-13$.

4. Leong K, Hawkshaw M, Dentchev D, Gupta R, Lurie D, et al. (2013) Reliability of Objective Voice Measures of Normal Speaking Voices. Journal of Voice 27: 170-176.

5. Roy N, Barkmeier-Kraemer J, Eadie T, Sivasankar M, Mehta D, et al. (2012). Evidence-Based Clinical Voice Assessment: A systematic Review. American Journal of Speech-Language pathology 22: 212-226. 